\title{
Alternative splicing of acrosin binding protein RNA transcript and its potential contributions to innovative cancer therapy
}

Cancer cells divide when there are gross chromosome abnormalities [1]. Biomarker discoveries have been used in cancer research for the early detection of cancer $[1,2]$. The cancer-testis antigens (CTAs) including acrosin binding protein (ACRBP), have gained much attention as cancer biomarkers because of their expression in many cancers including liposarcoma, hepatocarcinoma, colorectal cancer, and glioma [3-7]. High ACRBP expression can correlate with survival time and the duration of relapse of cancers after treatment with the anticancer chemotherapy agent paclitaxel $[1,8]$. ACRBP is necessary and sufficient for the paclitaxel resistance found in some cell lines [1]. The gene that encodes ACRBP is variously dentified as CT23, SP32, and OY-TES-1, is located in chromosome 12p12-p13 and includes 10 exons [7].

Splicing of primary RNA transcripts, i.e., removal of introns and joining of exons to produce mature mRNAs competent for translation into proteins, is a quasi-systematic step of gene expression in higher organisms. However, this process can follow alternative pathways or "alternative splicing". Alternative splicing makes it possible for cells to make many different proteins from a limited number of genes $[2,9]$. Therefore, alternative splicing of a given transcript can yield several distinct mRNAs encoding as many different proteins. Some of the alternative pathways during splicing process may be aberrant and cause diseases [2]. Thus, the aberrant expression of OY-TES-1 mRNA and protein, detected by reverse transcription polymerase chain reaction (RTPCR) and immunohistochemistry, was found to be correlated with the occurrence of colorectal cancer [5]. Using conventional RT-quantitative PCR, OY-TES-1 mRNA was detected at significantly higher levels in glioma tissues of patients with this neoplasm and serum samples from some of the patients with glioma, than it was in a panel of normal tissues (with the exception of the testis) including normal brain tissue [6].

In this issue, Zheng [10] reports the expression of newly discovered alternative splicing of ACRBP in 92 brain tumor specimens and three cell lines. Zheng designed new primers to examine the expression of the new splice variant in all the samples and correlated the relative expressions of variant with clinicopathological features of the patients (gender, age, and Karnofsky performance status), the tumor types (astrocytoma, glioblastoma, and medulloblastoma), and tumor grades. Zheng found a significant correlation between the relative expression of the newly discovered splicing variant of ACRBP with tumor types and tumor grades. The investigators concluded that the newly discovered splicing variant of ACRBP may have discriminative value for brain tumors. The finding has the potential to contribute to the discovery of molecular targeted therapies for brain tumors [10].

This implies that ACRBP may be useful as a biomarker to identify tumors as well as their associated genes and alternative-splicing defects. Understanding of ACRBP alternative splicing in cancer may be used as a clue for future research and clinical inquiry. Focusing on splicing regulators and their downstream targets can guide the way to a new understanding of the mechanisms of cancer and eventually lead to innovative cancer therapeutics [11].

\section{References}

[1] Whitehurst AW, Xie Y, Purinton SC, Cappell KM, Swanik JT, Larson $\mathrm{B}$, et al. Tumor antigen acrosin binding protein normalizes

* Correspondence to: Editorial Office of Asian Biomedicine, Faculty of Medicine, Chulalongkorn University, Bangkok 10330, Thailand, e-mail: abmjournal@chula.ac.th

O Open Access. ๑ 2020 Editorial Office of Asian Biomedicine, published by Sciendo. (๔) BY-NC-ND This work is licensed under the Creative Commons Attribution NonCommercial-NoDerivatives 4.0 License. 
mitotic spindle function to promote cancer cell proliferation. Cancer Res. 2010; 70:7652-61.

[2] Stamm S, Smith C, Lührmann R, editors. Alternative pre-mRNA splicing: theory and protocols. Weinheim, Germany: Wiley-VCH Verlag; 2012.

[3] Hemminger JA, Toland AE, Scharschmidt TJ, Mayerson JL, Guttridge DC, Iwenofu OH. Expression of cancer-testis antigens MAGEA1, MAGEA3, ACRBP, PRAME, SSX2, and CTAG2 in myxoid and round cell liposarcoma. Mod Pathol. 2014; 27:1238-45.

[4] Luo B, Yun X, Lin YD, Xiao SW, Yan GH, He SJ, et al. [Construction of eukaryotic expression vector encoding ACRBP and its expression in hepatocarcinoma cells]. Xi Bao Yu Fen Zi Mian Yi Xue Za Zhi [Chinese Journal of Cellular and Molecular Immunology]. 2011; 27:1072-4. [in Chinese, English abstract].

[5] Luo B, Yun X, Fan R, Lin Y-D, He S-J, Zhang Q-M, et al. Cancer testis antigen OY-TES-1 expression and serum immunogenicity in colorectal cancer: its relationship to clinicopathological parameters. Int J Clin Exp Pathol. 2013; 6:2835-45.
[6] Li X, Yan J, Fan R, Luo B, Zhang Q, Lin Y, et al. Serum immunoreactivity of cancer/testis antigen OY-TES- 1 and its tissues expression in glioma. Oncol Lett. 2017; 13:3080-6.

[7] Ono T, Kurashige T, Harada N, Noguchi Y, Saika T, Niikawa N, et al. Identification of proacrosin binding protein sp32 precursor as a human cancer/testis antigen. Proc Natl Acad Sci U S A. 2001; 98:3282-7.

[8] Kazemi-Oula G, Ghafouri-Fard S, Mobasheri MB, Geranpayeh L, Modarressi MH. Upregulation of RHOXF2 and ODF4 expression in breast cancer tissues. Cell J. 2015; 17:471-7.

[9] Baralle FE, Giudice J. Alternative splicing as a regulator of development and tissue identity. Nat Rev Mol Cell Biol. 2017; 18:437-51.

[10] Zheng B. Expression and clinical importance of a newly discovered alternative splice variant of the gene for acrosin binding protein found in human brain tumors. Asian Biomed (Research Review News). 2020: 14(6);243-52.

[11] Urbanski LM, Leclair N, Anczuków O. Alternative-splicing defects in cancer: splicing regulators and their downstream targets, guiding the way to novel cancer therapeutics. Wiley Interdiscip Rev RNA. 2018; 9:e1476. doi: 10.1002/wrna.1476 